\title{
Use of a halo frame for optimum intra- and post-operative management after scalp replantation/revascularization
}

\author{
R. Koul Ashok, Nahar Sushil, Valandi Beena, H. P. Kumar Praveen \\ Department of Plastic and Reconstructive Microsurgery, Sparsh Hospital, Bangalore, India
}

Address for correspondence: Dr. Sushil Nahar, Department of Plastic and Reconstructive Microsurgery, Sparsh Hospital, 29/P2, Narayana Health City, Bommasandra, Bangalore - 560 099, India. E-mail: nahardrsushil@yahoo.com

\begin{abstract}
We present a new technique for stabilizing an avulsed scalp during and after replantation/ revascularization. We used an aluminium "halo" frame with 4 screws. This technique can rigidly stabilize an avulsed scalp and eliminate the possibility of shearing/pressure necrosis. This device can make perioperative management easier and more comfortable for the patient and caregivers.
\end{abstract}

\section{KEY WORDS}

Scalp avulsion; scalp replantation; scalp revascularization; scalp stabilization

\section{INTRODUCTION}

major challenge in the successful replantation/ revascularization of an avulsed scalp is positioning of the patient's head during and after the operation, because:

1. Possibility of shearing between scalp and skull when the head is moved/rotated intra-operatively, leading to tearing of anastomosed vessels; and

2. Post-operatively, the possibility of necrosis of scalp over pressure-bearing areas.

\section{CASE REPORT}

An 18-year-girl presented to us with near total scalp avulsion due to machine belt injury [Figure 1a]. She

\begin{tabular}{|l|l|}
\hline \multicolumn{2}{|c|}{ Access this article online } \\
\hline Quick Response Code: & Website: \\
\hline & www.ijps.org \\
\cline { 2 - 2 } & Dol: \\
\hline
\end{tabular}

underwent scalp revascularization in which we used a "halo frame" to stabilize the scalp during and after operation [Figures 1c, d and 2a].

The device we used is a $10 \mathrm{~mm}$ thick aluminum bar bent into a U-shape. It has multiple-threaded holes in the axial plane, through which stainless steel screws are passed. Each screw is locked with a nut on each side. The fully assembled device weighs $475 \mathrm{~g}$ [Figure 2a].

\section{Operative steps}

1. The avulsed scalp was cleaned and shaved [Figure 1b]. The superficial temporal vessels were identified and tagged in the avulsed scalp and in both the pre-auricular regions.

2. The scalp was put in place and stapled at multiple points maintaining access to the vessels through oblique incisions.

3. The halo was attached to the skull, with the open end of the $U$ facing anteriorly, using 4 screws [Figure 1c and $\mathrm{d}$ ]. The marking for the placement of screws was done as follows [Figure 2c]: All the 4 screws were placed in the same axial plane about $3 \mathrm{~cm}$ above the upper margin of the helix. The 


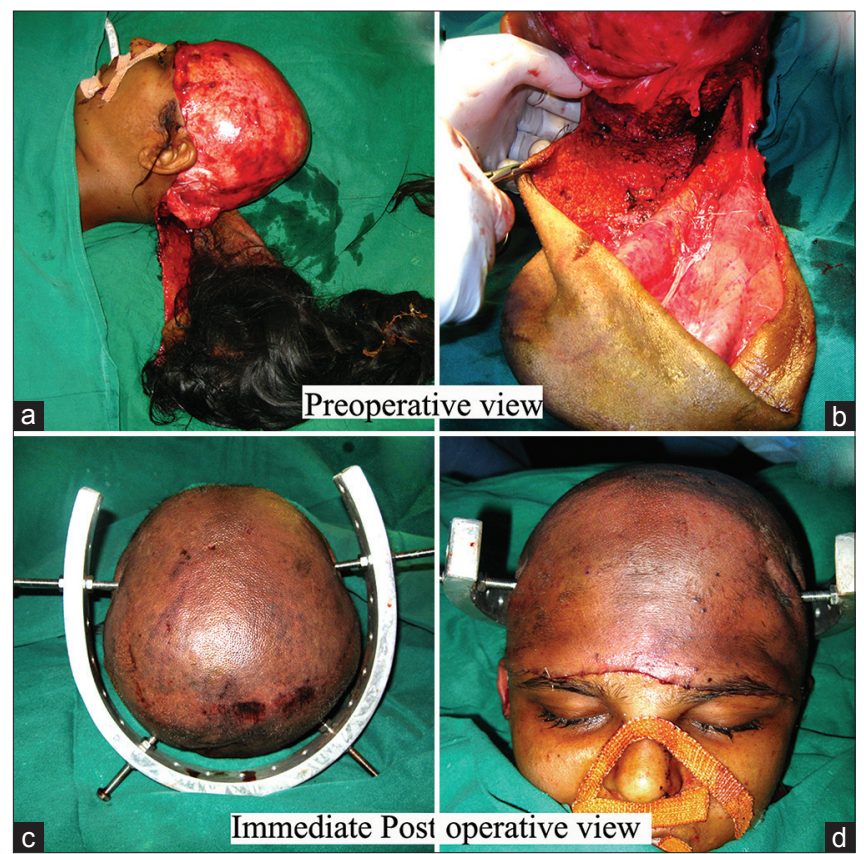

Figure 1: (a) Pre-operative view of avulsed scalp (b) Pre-operative view of avulsed scalp after shaving (c) Immediate post-operative cranial view of scalp with halo device in situ, and (d) Frontal view showing halo device in situ

anterior screws were placed about $4 \mathrm{~cm}$ in front of a vertical line passing through the root of helix, and the posterior screws about $3 \mathrm{~cm}$ behind this line. These points were chosen to avoid the (i) thin squamous temporal bone, (ii) the previously marked anterior and posterior branches of the superficial temporal vessels, and (iii) the major venous sinuses.

4. The screws were passed through small stab incisions in the scalp and gradually tightened by hand till the tip of the screw touched the outer table. Care was taken to rotate the screws in small increments, one after the other, so that all the 4 screws went to the same depth and the gap between the halo and the scalp was equal all around. Once the screw tip had touched the outer table, each screw was tightened further by one full turn (1 mm depth). At this point the halo had a firm grip on the skull without the screws having penetrated the outer table fully [Figure $2 \mathrm{~b}$ ]. The vascular anastomoses were carried out, and the skin edges closed.

5. Only a small dressing was applied along the suture lines and around the 4 screw entry points, leaving the entire replanted scalp exposed for easy monitoring [Figure 1c and $\mathrm{d}$ ].

Post-operatively the patient's head was allowed to rest on the halo, and the head end of the bed was kept elevated [Figure 1c]. From the first post-operative
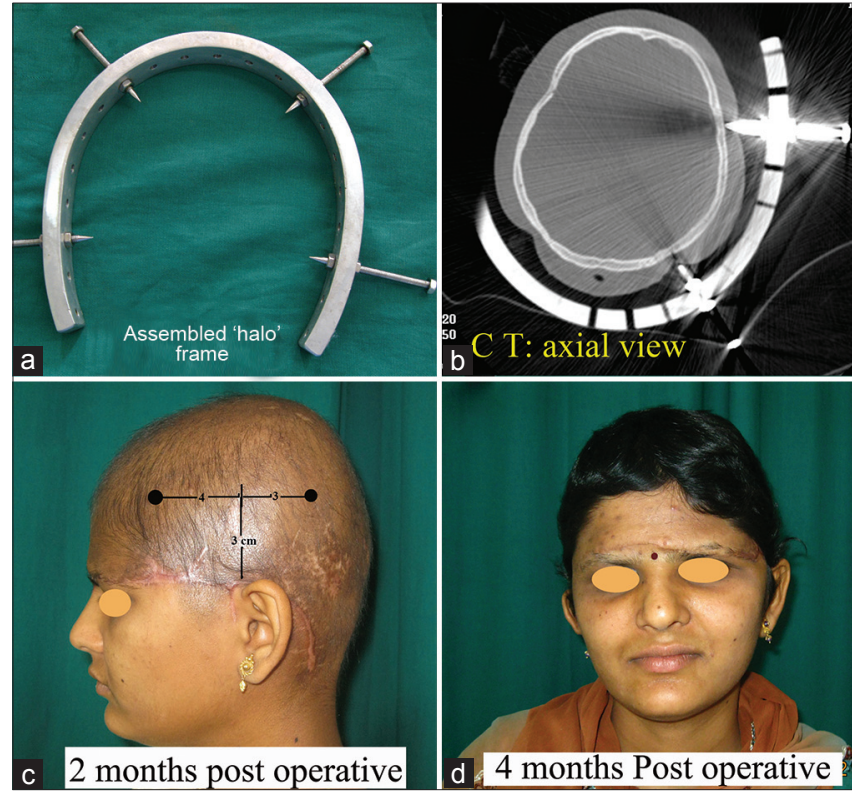

Figure 2: (a) Picture showing assembled halo device (b) Computed tomography scan axial view showing halo device's screw engaging outer cortex of cranium (c) 2-month post-operative: Lateral view showing marking

for screw entry point and (d) 4-month postoperative: Frontal view

day onwards, the patient was able to get up and walk around.

The whole of the scalp survived except for the partial thickness loss of two small patches where there had been direct deep grazing injury. The halo was removed at bedside, without any anesthesia, on the $14^{\text {th }}$ post-operative day.

\section{DISCUSSION}

From our experience of scalp replantation in the past, and as reported by others, replanted scalps are susceptible to shearing and avulsion, as well as pressure necrosis at occipital region..$^{[1]}$ One of the ways of avoiding these problems is to keep the patient in a sitting posture at all times. This is very difficult, especially in the early post-operative period. Once a scalp replant fails, it not only results in multiple stages of surgery, but also causes great financial loss and emotional trauma to the patient. ${ }^{[2]}$ Use of this halo device can make the intra- and post-operative management of scalp replantations easier and ensure more complete survivals [Figure $2 \mathrm{c}$ and $\mathrm{d}$ ].

\section{SUMMARY}

We present a new technique for stabilization of a replanted scalp and avoiding pressure on the scalp post-operatively. This technique is safe, simple and 
has the additional advantage of avoiding a bulky dressing and allowing continuous easy monitoring of vascularity.

\section{REFERENCES}

1. Sabapathy SR, Venkatramani H, Bharathi RR, D'Silva J. Technical considerations in replantation of total scalp avulsions. J Plast Reconstr Aesthet Surg 2006;59:2-10.

2. Mowlavi A, Bass MJ, Khurshid KA, Milner S, Zook EG. Psychological sequelae of failed scalp replantation. Plast Reconstr Surg 2004;113:1573-9.

How to cite this article: Koul AR, Nahar S, Valandi B, Praveen Kumar HP. Use of a halo frame for optimum intra- and post-operative management after scalp replantation/revascularization. Indian J Plast Surg 2012;45:560-2.

Source of Support: Nil, Conflict of Interest: None declared. 